\title{
DILG NEGROS OCCIDENTAL CONTACT TRACER INFORMATION MANAGEMENT SYSTEM
}

\author{
John Christopher V. Reguindin ${ }^{1}$, Reymund L.Sabay, $\mathrm{PhD}^{2}$, Dennis V. Madrigal $\mathrm{PhD}^{3}$ \\ ${ }^{123}$ University of Negros Occidental-Recoletos, Bacolod City, Philippines \\ ${ }^{1}$ jcreguindin@gmail.com,${ }^{2}$ iamreymund@gmail.com, ${ }^{3}$ dennis_madrigal @yahoo.com, \\ ${ }^{1}$ https://orcid.org/0000-0003-4507-6159, ${ }^{2}$ https://orcid.org/0000-0003-3313-3144, \\ ${ }^{3}$ https://orcid.org/0000-0001-5548-2682
}

\begin{abstract}
COVID-19 pandemic reshapes the use of technology and innovation in an organization. Organizations are adopting and utilizing technologies in their dayto-day operations. Information Systems offer a wide range of solutions in terms of data management and interconnecting people with the use of a system. Its use was proven to enhance and improve the productivity of an organization in this pandemic. These promising results led the researcher to develop the Department of the Interior and Local Government (DILG) Negros Occidental Contact Tracer Information Management System (CTIMS). The CTIMS is a web application that enables DILG Negros Occidental Personnel to manage and facilitate all DILG Hired-Contact Tracers (CT) in the Province of Negros Occidental. The automated system made the data collection easy and error-free, streamlined reporting, and eliminated the time-consuming process of consolidating the Accomplishment Reports (ARs) from the Field and Provincial Offices. The document tracker feature replaced the manual entry in the logbook. It also improved the received and released document reporting. It improved the processes of the CT Task team compared to the manual operations and is expected to increase the productivity, effectivity, and efficiency of DILG Negros Occidental.
\end{abstract}

Keywords: Information Systems, Contact Tracers, Province of Negros Occidental, Department of the Interior and Local Government, Local Government Units, Data Management, COVID 19 Pandemic, Accomplishment Reports, Bayanihan to Heal as One Act

\section{Introduction}

The highly contagious nature of COVID-19 has been one of the reasons the virus developed into a full-blown pandemic (Mack, 2020). Studies show that effective contact tracing helps the community carefully identify, isolate, and prevent or slow down the spread of the COVID-19 virus. Contact tracing is the process of identifying, assessing, and managing people exposed to the confirmed COVID-19 contact to prevent transmission. When it is applied in an organization, it will lessen or slow down or stop the transmission of the virus. Contact tracing has been a central pillar of the public health response to COVID-19 (Fetzer \& Graeber, 2021) and is essential to reduce the spread of the COVID-19 virus. Furthermore, in response to the coronavirus pandemic, 
public health leaders call for communities around the country to ramp up capacity and implement a massive contact tracing effort to control the spread of the coronavirus. The response and recovery from the effect of COVID-19 will continue to present federal agencies with unprecedented challenges, as well as opportunities for improvement, that require new processes and practices such as COVID-19 contact tracing to keep the workforce and the public safe (Federal Information \& News Dispatch Inc., 2021).

The National Government through the Department of the Interior and Local Government (DILG) provided guidelines in the composition and hiring of Contact Tracers (CT) Teams. However, due to the limitation to hiring additional CT Teams, an amount of P5B was allocated for the recruitment of 50,000 Contact Tracers (CT) nationwide under RA 11494, known as Bayanihan to Heal as One Act on September 30, 2020. The DILG-hired CTs will augment the operations of the Local Government Units (LGUs) through their Local Health Office (LHO).

The Province of Negros Occidental was allocated 1,000 CTs to augment the CT efforts of its component LGUs for three months and was trimmed down to 295 CTs last January 2021. Considering the distance of the LGUs from the DILG provincial office and the number of CTs to be monitored, the submission and consolidation of reports have become a problem. There were also delays in submission because consolidation and monitoring were done manually. The absence of a reporting system has brought many problems in the transmission of accomplishments.

Several studies about contact tracing, such as the study of the utilization of digital technology in the context of COVID-19, mark the ushering in of a promising new milestone in implementing mass interventions. Big data and machine learning have played integral roles in the efficient prevention and management of the new SARS-CoV-2 disease (Vaishya et al., 2020).

In 2010, a consortium of researchers in the United Kingdom allowed users to install a mobile software application called the FluPhone to anonymously collect information on social encounters using Bluetooth, Global Positioning System (GPS) coordination, and self-reported data. Successively, this information aided in developing predictive models of the influenza virus transmission patterns within each community (University of Cambridge, 2011).

The utilization of digital technology would result in a promising outcome in addressing the current problems faced by DILG Negros Occidental. Hence, the development of the Contact Tracer Information Management System (CTIMS) will aid and address the pressing problems of DILG Negros Occidental in the management of the DILG-Hired CTs.

The CTIMS will increase the productivity of DILG employees in handling the CTs. It will reduce the probability of human error and enhance teamwork and collaboration within the team. In addition, CTIMS would enhance organizational management, help in the decision-making of the top management, and increase the output and productivity rate and help the team achieve the objectives, monitor and track CT information. Automating the current processes of the DILG Negros Occidental would help the team in terms of speedy processing of documents and storing relevant information. Another advantage is the elimination of the redundant steps in the process flow of documents and information of the CTs. 
The objective of the system is to establish an Information System that would have to create a centralized database for CTs that will eliminate the probability of data redundancy and loss, and the consolidation of the essential data. Next, is the seamless storing and retrieval of the consolidated CT Accomplishment Information that would eradicate the time-consuming process of collecting the CT to the Field Offices. Lastly, the creation of a Document Tracker for Administrative Documents such as the CTs Daily Time Records (DTR), Travel Claims, and Communication Allowance that would address the manual process of monitoring the CTs' documents and manual entry in the logbook for every transaction.

This system is the pioneer system in the Philippines when it comes to the management of DILG-hired CTs. The focus on the role of the DILG during the time of the COVID-19 pandemic is timely and critical as this is the executive branch of government that is extensive and overlapping - from national security to basic service delivery, from national to local governments. It is also a key agency to the whole-of-nation approach in governance that entails collaboration and participation from all sectors and stakeholders (Villarin, 2020).

The DILG, in coordination with LGUs, was tasked to lead the contact-tracing efforts of the government (IATF Reso. 25, 2020). With the approval of the Republic Act 11494 or the Bayanihan Act, the recruitment, training, compensation, monitoring, logistics, and operational expenses of CTs were ordered to Regional Offices.

Thereafter, the DILG Negros Occidental Provincial CT Task Team was created and mandated to oversee the overall operations on the recruitment, management, and deployment of CTs and facilitate the submission of accomplishment reports (AR) and all administrative requirements to support payment of salaries and other authorized claims of CTs pursuant to Regional Memorandum dated October 12, 2020, entitled "Guidelines on the Management and Deployment of DILG-Hired Contact Tracers".

\section{Framework of the Study}

The CT Task Team faced difficulties in managing around 1000 CTs hired during the last quarter of 2020. The team created different databases as data gathering tools for CTs Information. The databases were prone to data loss because of the numerous databases. Second, the CTs were required to submit an AR every month. However, some CTs failed to submit the appropriate report that resulting in the delay of the release of the salary. Lastly, the evaluation of the CT faced many questions since their performance was rated based on the discretion of the Field Officer (FO). The scores were encoded through Google Drive. Some CTs had issues on the evaluation sheet, compromising the security of the data. 
Figure 1 illustrates the Context Diagram of the DILG Negros Occidental CT Information Management System (CTIMS). Data Flow Diagram (DFD) is a graphical diagram for specifying, constructing, and visualizing the model of a system (Ibrahim et al, 2010). This figure describes the flow of data consisting of input, processes, and output in the system.

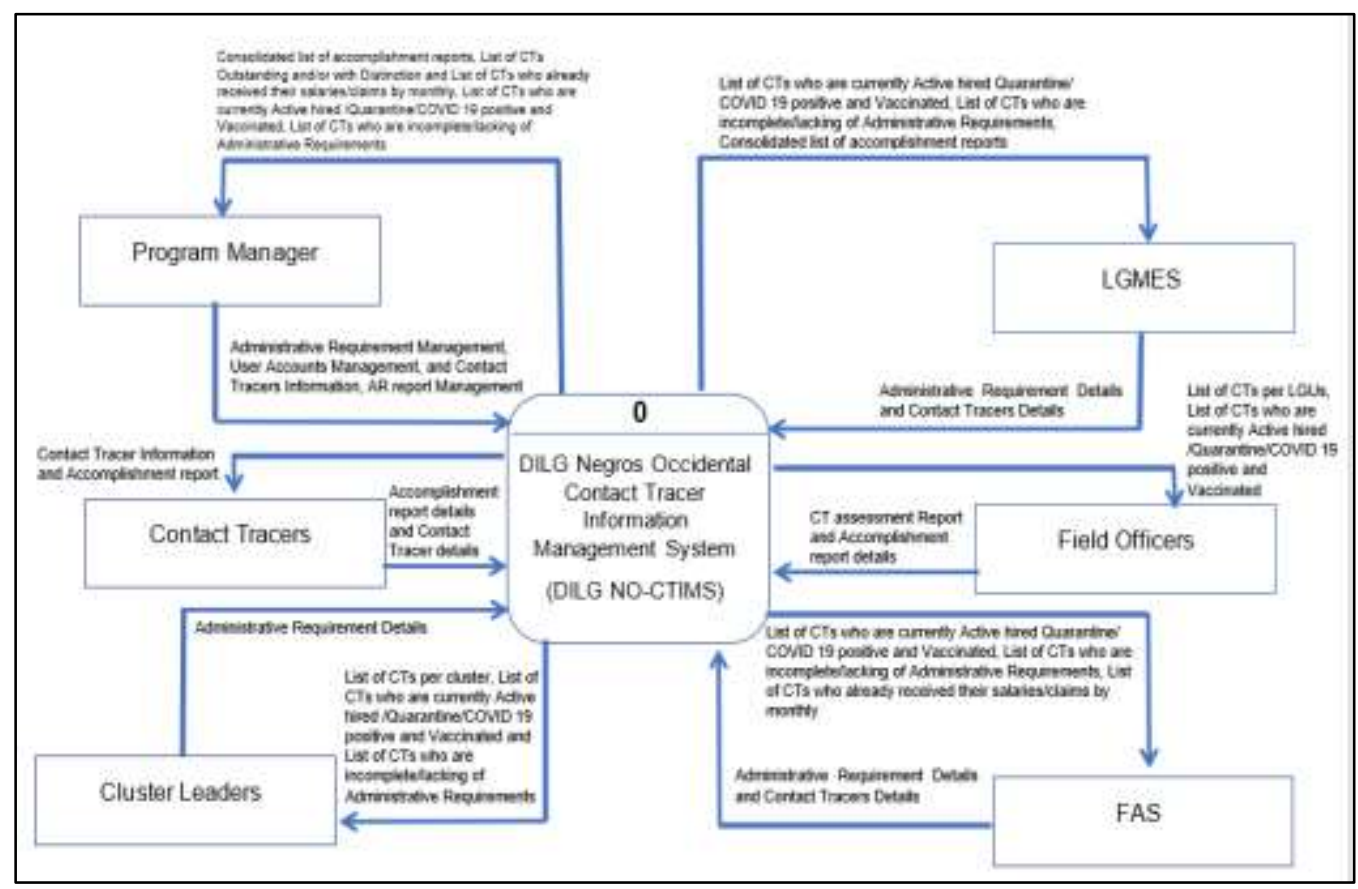

Figure 1. Context Diagram of DILG Negros Occidental CTIMS

The significance of capturing data plays a significant role in the development of the system. Good data are data that are documented, stored, and accessible. This is based on the premise of making the data available for future research and evaluation for purposes of reproducibility, research integrity, further research, or challenge and decision-making of a government agency (Dunie, 2017).

One of the most important parts of research is data capture. Proper usage of the data sets and everything is in order. Governmental agencies have been issuing policies on data and management for a much longer time (Dunie, 2017). The DILG Negros Occidental CT Task Team uses forms to process the administrative requirements of the CTs in terms of their salaries, premiums, and other benefits stated in the contract. To monitor their progress, the CTs are being observed using the evaluation tool that would measure the accomplishment and attainment of their task.

The Contract provides the documents to be submitted to the Regional Office to support their salaries and claims such as the ARs, DTRs, and other related documents.

The CT AR is composed of the questions answerable in a quantitative manner. This form requires the signature of the CT, the City/Municipal Local Government Operations Officer (LGOO) assigned in the LGU, and the Local Epidemiology and Surveillance Officer (LESO) or Team Leader. 
In receiving the documents from the Contact Tracers, each section is recording in their logbooks the entry of a document. The data in the logbook are manually written by the assigned receiving personnel. The logbook consists of columns that contain the Date, CT's Name, LGU, and documents submitted by the $\mathrm{CT}$ and the concerned $\mathrm{CH}$ for review.

\section{Methods}

\section{Software Development Life Cycle}

The researcher utilizes Agile Development for the software development method. An agile development model is an adaptive approach that will suit the project since there will be incremental development along the way. This development method is flexible and can adopt new developments and new features. The product is tested very frequently through the release iterations, minimizing the risk of any major failures in the future (Sharma, et al., 2012).

Customer interaction is the backbone of this Agile methodology, and open communication with minimum documentation is the typical feature of the Agile development environment. The Agile teams work closely with one another and are most often located in the same geographical location (SDLC-Agile Model, 2001).

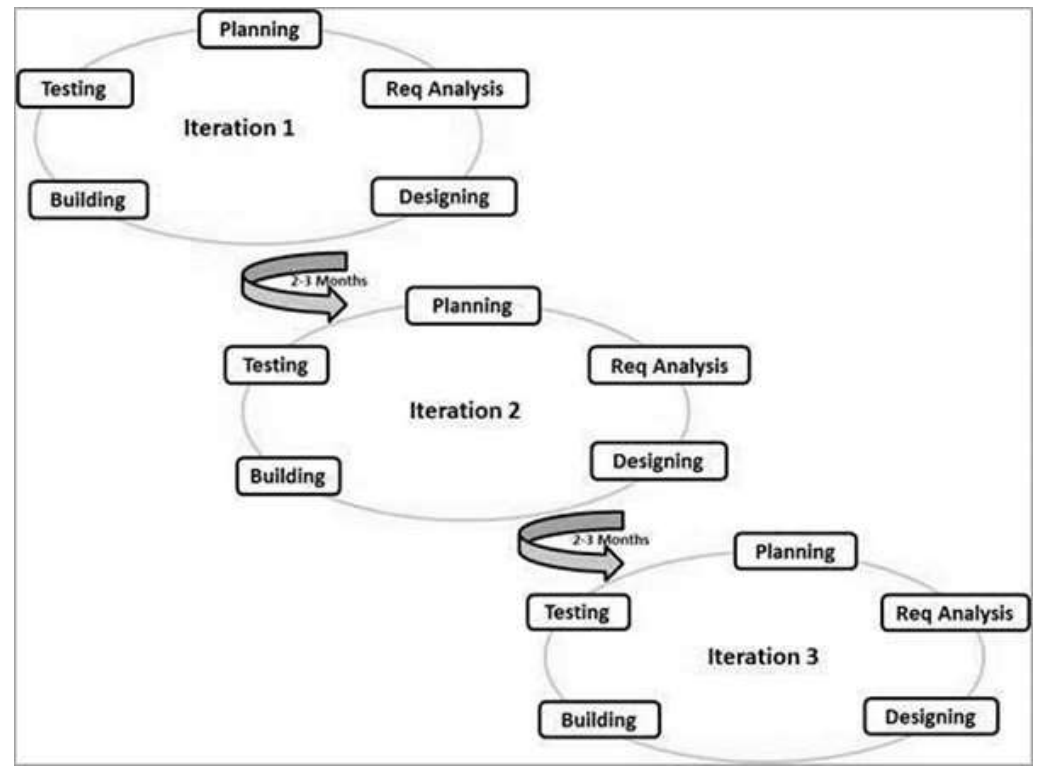

Figure 2. System Development Life Cycle - Agile Model

The system is expected to promote collaboration within the CTs and the CT Task, Team. Series of interviews and Focus-Group Discussion (FGD) with the CT Coordinator of each LGUs and the CTs assigned in the Provincial Office and identified the processes to be automated in the system and discuss the flow of the current process, processes should be done, processes should be removed, and processes that should be improved or revised.

Requirement analysis is one of the key challenges in software development projects (Demirel \& Das, 2018). Based on the interview with the PM and the CT Task Team, the manual process of data banking the CTs information, AR uniformity, and tracking of the administrative documents are their primary concerns. 
After the requirements were gathered, the information gathered is transformed into system design. Software design is a complex cognitive process in which decision-making plays a major role, but our understanding of how decisions are made is limited, especially with regard to reasoning with design problems and formulation of design solutions. (Tang, et al.,2010). This is where the interfaces, the components of the proposed feature of the system, display the relevant information in the system.

The development phase is where the researcher starts to construct and code the system based on the Software design. This is a crucial stage since the researcher should choose an appropriate programming language that is suitable for the software design.

Software Testing is the process to check whether the software is defect-free or not (Uddin \&Anand, 2019). This part is where the proposed system will be presented, and the application will be tested as to the functionality, detecting bugs, revision, and other related concerns.

Most of the time, the reliability that the users focus on the hardware are durability, physical status, longevity, and ability to wear out. Unlike software, they are being measured based on their complexity, and the conduct of system testing would somehow increase its reliability. Lowell Jay Arthur's instrument was utilized to measure the performance of the system. The researcher initiated a survey through Google forms to test the system based on 26 different criteria in testing the system. The respondents answered the evaluation based on the given question and criteria in the system. After that, the researcher computed the evaluation score of the 30 respondents/evaluators of the system.

Acceptance testing is the validation of the actual behavior of the implementation under test against the requirements of stakeholders (Shi \& Corriveau, 2017). This is where the system will be staged again by a user and/or the employee to test the system further and issue the system's utilization.

\section{Usage Scenario}

Use case diagrams are used to gather the requirements of a system including internal and external influences. These requirements are mostly design requirements. So, when a system is analyzed to gather its functionalities use cases are prepared and actors are identified (Waykar, 2015). Figure 3 shows the use case diagram of the DILG Negros Occidental CTIMS. There are six (6) users in the system with different roles and responsibilities.

The DILG Negros Occidental CTIMS can only be accessed by the authorized personnel: the CTs, DILG employees from FAS, LGMES, FO, CH, and the administrator. The administrator has access to all the modules in the system and manages all the users in the system. The CTs are tasked to update their personal information, generate accomplishment reports, and track documents. FAS and LGMES can access is to Receive Documents and Generate Reports while the $\mathrm{CH}$ can Receive Documents, Generate Reports, Track CT Documents, View Evaluation Grade. FOs can Generate Reports, Evaluate CT, Track Administrative Documents. 


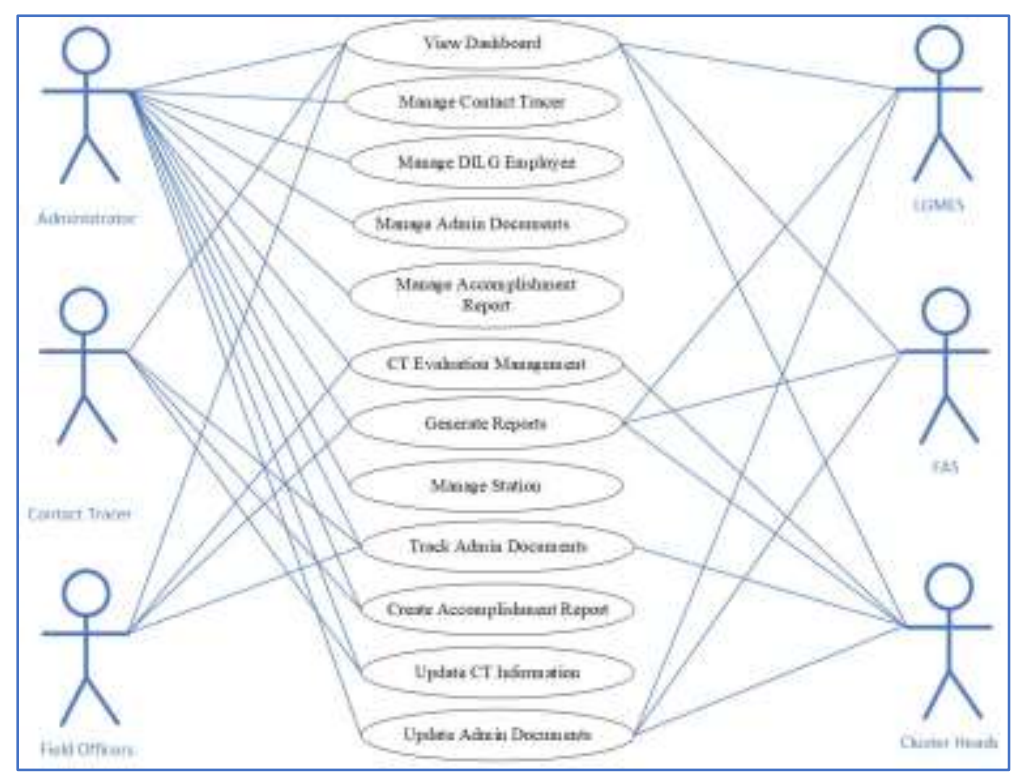

Figure 3. Use Case Diagram

\section{Project Management}

The process of developing a comprehensive project cost estimate is critical for a project to be adjudged successful on completion (Amade \& Akpan,2014). The determination of the budget for the system requires a thorough analysis since it plays a critical role in project planning. In this phase, the researcher identifies the individual material resources or work items over time. The cost for the development and its implementation, the operations, and the maintenance costs were computed and documented. This would justify the budget that the office shall allocate for the development of the system. Inaccurate estimates may lead to overruns and disappointment in the output, while inaccurate high estimates can discourage the top management from funding the system.

Development cost is mainly referred to as the cost of an organization in the development of a system. The DILG Negros Occidental CTIMS has an estimated Php 193,500.00 for the development costs. This one-time cost includes the personnel in developing the system, the equipment, and the supplies. While the Projected Annual Operating Costs mean the annual expenses incurred by the organization after the development of the system. The DILG Negros Occidental CTIMS has an estimated Php 26,500.00 for the Annual Operating Cost. This includes the electric bill, the payment for the on-call service maintenance, Internet Connection, and the payment of the domain server.

\begin{tabular}{|c|c|}
\hline \multicolumn{2}{|l|}{ Development Costs } \\
\hline \multicolumn{2}{|l|}{ Personnel: } \\
\hline $\begin{array}{l}1 \text { System Analyst (6 months @ Php } \\
12,000.00 / \mathrm{mo} \text { ) }\end{array}$ & Php 72,000.00 \\
\hline $\begin{array}{l}1 \text { Programmer (6 months @ Php } \\
\text { 10,000.00/mo) } \\
\text { Equipment: }\end{array}$ & Php 60,000.00 \\
\hline
\end{tabular}




\begin{tabular}{|lll|}
\hline \multicolumn{1}{|l}{ 1 Desktop Computer } & Php 45,000.00 \\
$\quad$ Printer & Php 10,000.00 & \\
Supplies: & Php 1,200.00 & \\
$\quad$ 1 box of A4 Bond Paper & Php 5,000,00 & \\
$\quad$ Printer Ink & Php 300.00 & Php 193,500.00 \\
$\quad$ Box of Ballpoint Pen & & \\
Total Development Cost & & \\
Projected Annual Operating Costs: & & \\
Personnel: & & \\
$\quad$ On-Call Service Maintenance (Php & Php 7,000.00 & \\
1,000/request) & & \\
Expenses: & & Php 26,500.00 \\
$\quad$ Monthly Bill (Php 1500.00/month) & Php 18,000.00 & Php 220,000.00 \\
Domain Server & Php 1,500.00 \\
Total Project Annual Operating Cost & & \\
Total Proposed System Budget & & \\
\hline
\end{tabular}

\section{Table 1. Proposed System Budget}

After the identification of the proposed budget, the Project Cost-Benefit Analysis (CBA) can now be initiated. CBA is an orderly process that a specific organization utilizes to examine whether a specific project or system shall be implemented. This analysis portrays the potential benefits expected for the system to deliver versus the development and operation costs. Based on the analysis conducted by the researcher.

The decision of investment is a strategic decision, and it is an integral part of the general policy of the company. Return of Investment (ROI) is analyzed, highlighting the advantages and limitations of its use. Aspects related to how the size of the ROI indicator is influenced by the method of valuation of assets are highlighted as well as the method of calculation for the working capital (Zamfir, et al., 2016). Based on the Cost-Benefit Analysis, the ROI is $1.16 \%$. It was computed by dividing the cumulative lifetime adjusted cost benefits by the cumulative time adjusted cost over a lifetime. This simply means that it is a good investment in the organization.

The Net Present Value (NPV) method, as an investment appraisal or capital budgeting technique, shows how an investment project affects company shareholders' wealth in present value terms. Maximizing shareholders' wealth is an important goal for management, and investment projects with positive NPV are wealth enhancing and should be accepted (Jory et al., 2016). The result of the computation in this project is Php 166,190.34.

The Payback Period Analysis (PBP) technique is based on how much time the project needs to generate cash flows sufficient to recover the cost of investments. It can also be used as a criterion for accepting or rejecting projects if the PBP is higher or lower than a certain number of years previously denied and to differentiate between projects (Al-Ani, 2015). It gives the organization the timeframe as to when the project will start gaining profit. According to the CBA, the estimated period will be around 3 years and 9 months. 
Project scheduling is just as important as cost budgeting as it determines the timeline, resources needed, and reality of the delivery of the project. Project managers with experience can properly dictate the tasks, effort, and money required to complete a project (Scott, 2020).

Based on the statement by Scott, project scheduling plays an essential role in the development of the system. This would ensure that the system will have its direction and goal to be achieved within a specific time.

The researcher used a Gantt chart to demonstrate the series of activities incurred from the start until the end of the project. The said chart will serve as the tracker for the system development activities to ensure that it is by the schedule.

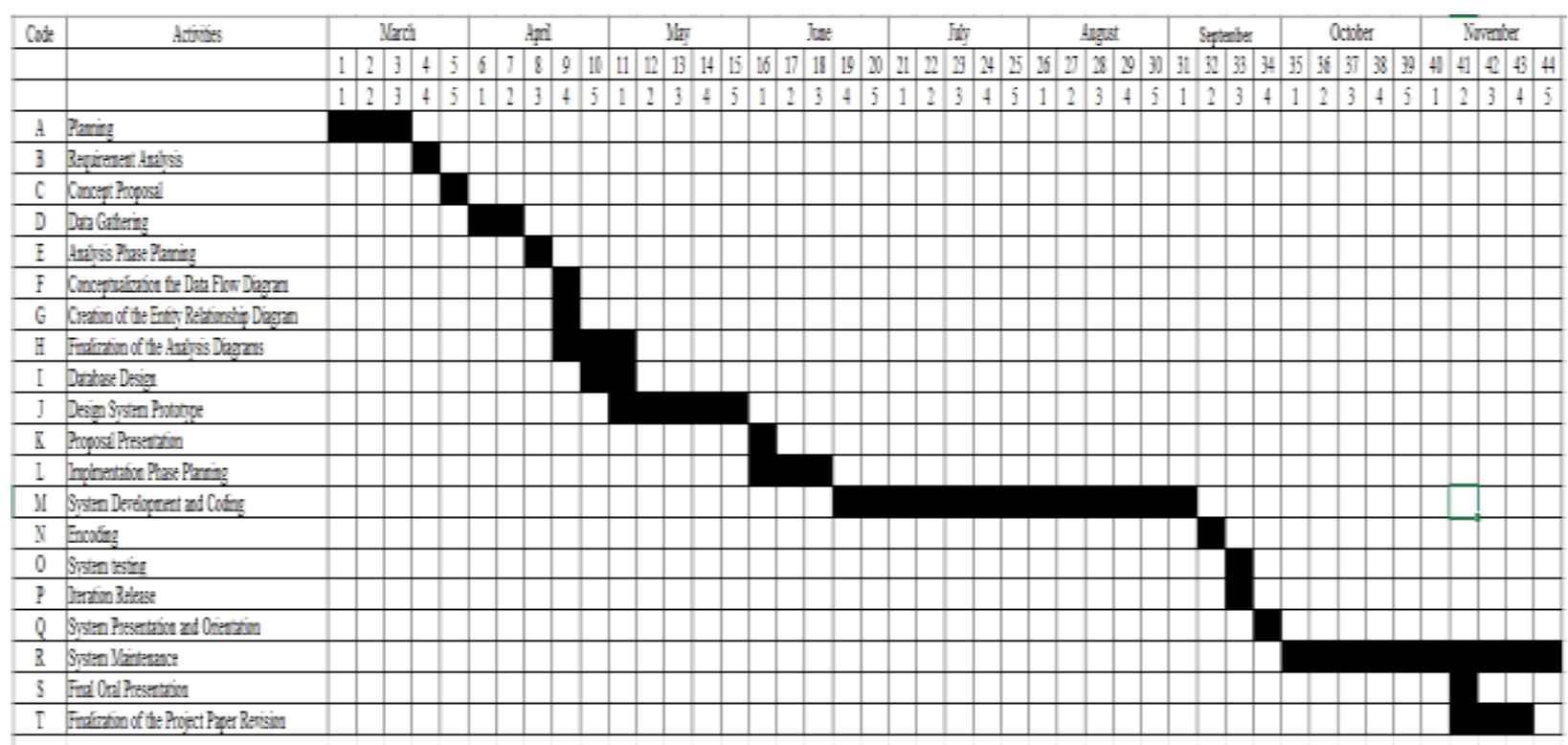

Figure 4. Gantt Chart

Resource planning is a common process critical to the success of all IT projects. It is supported by well-developed methods, processes, and tools (Pountney, 2013). To maximize the performance and the features of the DILG Negros Occidental CTIMS. Software and Hardware requirements shall be met. The researcher recommends the following software and hardware requirements for the development and the production of the DILG Negros Occidental CTIMS to function and perform properly.

\begin{tabular}{|l|l|}
\hline Operating System: & Windows 7 or higher \\
\hline Browser: & Google Chrome/Firefox \\
\hline Database Connection: & XAMPP Server \\
\hline Data Storage: & MySQL Database \\
\hline
\end{tabular}

Table 2. Software Requirements 


\begin{tabular}{|l|l|l|}
\hline & \multicolumn{1}{|c|}{ Client-Side } & \multicolumn{1}{c|}{ Server Side } \\
\hline Processor: & Intel Core i3 2.0 GHz & Intel Core i3 2.0 GHz \\
\hline Memory: & 4GB RAM or higher & 8GB RAM or higher \\
\hline Hard Disk: & 320GB HDD or higher & 320GB SSD or higher \\
\hline Monitor: & Any compatible monitor & Any compatible monitor \\
\hline Other: & $\begin{array}{l}\text { Any compatible mouse and } \\
\text { keyboard }\end{array}$ & Any compatible mouse and keyboard \\
\hline
\end{tabular}

Table 3. Hardware Requirements

\section{Software Metrics}

Size-oriented metrics are derived by normalizing quality and productivity point metrics measures by considering the size of the software that has been produced (Madhurihammad, 2020). These metrics use the Lines of Code (LOC) in the source file computation for the basis of its measurement.

\begin{tabular}{|c|c|c|c|c|c|c|c|}
\hline System & LOC & Effort & $\begin{array}{c}\text { Php } \\
(000)\end{array}$ & $\begin{array}{c}\text { Pp. } \\
\text { Doc. }\end{array}$ & Errors & Defects & People \\
\hline $\begin{array}{c}\text { DILG Negros } \\
\text { Occidental Contact } \\
\text { Tracer Management } \\
\text { System }\end{array}$ & 299,396 & 90 & 132 & 160 & 165 & 74 & 1 \\
\hline
\end{tabular}

Table 4. Size-Oriented Metrics of DILG Negros Occidental CTIMS Table

Table 5 shows the Size-Oriented Project Measurement Table. The values in the equation were derived from Table 4. This table serves as a guide to measure the Errors per KLOC, Defects per KLOC, Php per KLOC, Page of Documentation per KLOC, Errors per Day, LOC per Day, and Php per Day.

\begin{tabular}{|l|l|c|c|}
\hline \multicolumn{1}{|c|}{ Measurement Subjects } & \multicolumn{1}{|c|}{ Formula } & Equation & Value \\
\hline 1. Errors per KLOC & Errors/KLOC & $165 / 299,396$ & $1,814.52$ \\
\hline 2. Defects per KLOC & Defects/KLOC & $74 / 299,396$ & $4,045.89$ \\
\hline 3. Php per KLOC & Php/LOC & $132,000 / 299,396$ & 2.26 \\
\hline 4. Page of Documentation per KLOC & Pp. Doc/KLOC & $160 / 299,396$ & 1871.22 \\
\hline 5. Errors per Day & Errors/Effort & $165 / 90$ & 1.83 \\
\hline 6. LOC per Day & LOC/Effort & $299,396 / 90$ & $3,326.62$ \\
\hline 7. Php per Day & Php/Effort & $132 / 90$ & $1,466.66$ \\
\hline
\end{tabular}

Table 5. Size-Oriented Project Measurement Table 
The Function Oriented Metrics are used to measure the functionality delivered by the application using function points. These metrics have four stages of project development: Requirement Analysis, System Design, Coding, and System Testing.

Table 6 illustrates the total number of days of the project completion. This table covers the number of days from the Requirement Analysis, Design, Coding, and Testing. The Implication Analysis shows the project cost that can be identified by multiplying the rate and the project duration.

\begin{tabular}{|c|c|c|c|c|}
\hline Function & $\begin{array}{l}\text { Requirement } \\
\text { Analysis }\end{array}$ & Design & Coding & Testing \\
\hline \multicolumn{5}{|l|}{ Input } \\
\hline Data Entry & 9 & 7 & 7 & 1 \\
\hline \multicolumn{5}{|l|}{ Output } \\
\hline Reports & 7 & 7 & 3 & 2 \\
\hline \multicolumn{5}{|l|}{ Transactions } \\
\hline CT Management & 7 & 5 & 7 & 2 \\
\hline $\begin{array}{l}\text { Management of Financial } \\
\text { and Admin Documents }\end{array}$ & 9 & 7 & 7 & 2 \\
\hline $\begin{array}{l}\text { Monitoring, Evaluation, and } \\
\text { Assessment of CT } \\
\text { Accomplishment }\end{array}$ & 15 & 5 & 20 & 2 \\
\hline \multicolumn{5}{|l|}{ Screen Layout } \\
\hline Contact Tracer Page & 2 & 2 & 2 & \\
\hline Field Officer Page & 3 & 3 & 5 & 1 \\
\hline Cluster Head Page & 4 & 3 & 5 & 2 \\
\hline Receiving Officer Page & 2 & 2 & 2 & 1 \\
\hline Administrator Page & 5 & 4 & 7 & 2 \\
\hline Total \# of Days & 63 & 45 & 65 & 15 \\
\hline \multicolumn{5}{|l|}{ Implication Analysis } \\
\hline Rate & \multicolumn{3}{|c|}{ : Php 1000.00 per day } & \\
\hline Project Cost & \multicolumn{4}{|c|}{$: 188$ days $*$ Php 1000.00 per day $=$ Php $\mathbf{1 8 8 , 0 0 0}$} \\
\hline Project Duration & \multicolumn{4}{|c|}{$\begin{array}{l}: 188 \text { days } * 7 \text { working days per week }=26 \text { Weeks } \\
\text { and } 6 \text { Days }\end{array}$} \\
\hline
\end{tabular}

Table 6. Function Oriented Metrics

The most widely used standard software size metric throughout the industry is Function Points (Schofield, 2007). Function Point measurement is not simple and requires expertise in software analysis (Irawati \& Mustofa, 2012). The function point computation refers to the number of inputs, outputs, user inquiries, files, and external interfaces in the system. The researcher made an inventory of the values.

Table 7 illustrates the computation of the Function Point. The total number of Inputs is 60, the number of outputs is 23 , the number of user inquiries is 24 , and the number of files is 8 with no external interface. 


\begin{tabular}{|l|c|c|c|c|c|}
\hline \multirow{2}{*}{ Measurement Parameter } & \multirow{2}{*}{ Count } & \multicolumn{3}{|c|}{ Weighting Factor } & \multirow{2}{*}{ Total } \\
\cline { 3 - 6 } & & Simple & Average & Complex & \\
\hline Number of Inputs & 60 & 3 & 4 & 6 & 180 \\
\hline Number of Outputs & 23 & 4 & 5 & 7 & 92 \\
\hline Number of User Inquiries & 24 & 3 & 4 & 6 & 96 \\
\hline Number of Files & 8 & 7 & 10 & 15 & 56 \\
\hline $\begin{array}{l}\text { Number of External } \\
\text { Interfaces }\end{array}$ & 0 & 5 & 7 & 10 & 0 \\
\hline Total Count & & & & 424 \\
\hline Complexity Multiplier & & & & 1.15 \\
\hline Total Function Point & & & & 487.6 \\
\hline
\end{tabular}

\section{Table 7. Function Points Computation}

In measuring the function points, Complexity Adjustment Responses should be present. The Complexity Adjustment Responses are composed of 14 questions, and each question is evaluated using the rating scale from zero to five (0-5). Five (5) serves as essential, Four (4) for significant, Three (3) for Average, Two (2) for Moderate, One (1) for Incidence, and Zero (0) for No Influence. The sum of all the ratings is called the Complexity Multiplier $\left(\sum \mathrm{F}_{\mathrm{i}}\right)$.

\begin{tabular}{|l|l|c|}
\hline$\#$ & Complexity Adjustment Responses & Ratings \\
\hline 1 & Does the system require reliable backup and recovery? & 4 \\
\hline 2 & Are data communications required? & 4 \\
\hline 3 & Are there distributed processing functions? & 4 \\
\hline 4 & Is performance critical? & 3 \\
\hline 5 & Will the system run in an existing, heavily utilized operational environment? & 2 \\
\hline 6 & Does the system require online data entry? & 4 \\
\hline 7 & $\begin{array}{l}\text { Does the online data entry require the input transaction to be built over multiple } \\
\text { screens or operations? }\end{array}$ & 4 \\
\hline 8 & Are the master files updated online? & 4 \\
\hline 9 & Are the inputs, outputs, files, or inquiries complex? & 3 \\
\hline 10 & Is the internal processing complex? & 3 \\
\hline 11 & Is the code designed to be reusable? & 4 \\
\hline 12 & Are conversion and installation included in the design? & 3 \\
\hline 13 & Is the system designed for multiple installations in different organizations? & 4 \\
\hline 14 & Is the application designed to facilitate change and ease of use by the user? & 4 \\
\hline Count Total $\left(\sum \mathrm{F}_{\mathrm{i}}\right)$ & $\underline{\mathbf{5 0}}$ \\
\hline $\begin{array}{l}\text { Function Points Formula: } \\
\text { FP }=\text { Total Count } *\left[0.65+0.01\left(\sum \mathrm{F}_{\mathrm{i}}\right)\right]\end{array}$ & \\
$=424 *[0.65+0.01(50)]$ & \\
& $=424 * 1.15$ \\
$=487.6$ & \\
\hline $\begin{array}{l}\text { System Cost }=487.6 * 800 / \mathrm{FP} \\
=\mathbf{3 9 0 , 0 8 0}\end{array}$ & \\
\hline
\end{tabular}

Table 8: Complexity Adjustment Responses

Rating Scale:

0 - No Influence, 1 - Incidence, 2 - Moderate, 3 - Average, 4 - Significant, 5 - Essential 


\section{Results and Discussion.}

Based on the evaluation and software validation shown in Table 9, almost all of the criteria received a high rating. The criteria that received a good rating are the following: Accuracy, Audibility, Error Tolerance, Hardware Dependence, Instrumentation, and Modularity. The criteria that received the highest rating were Consistency and Understandability since the system was designed to be user-friendly and easy to understand. The lowest rating received was error Tolerance that has a rating of 4.03. The Communication, Completeness, Conciseness, Consistency and Understandability, Controllability, Data Commonality, Decomposability, and Error Tolerance received a very good rating that ranges around 5.00-4.21.

The results indicate that the CTIMS suits the need of the organization. The compactness of the program, the design, documentation techniques, and reporting are well understood. The output of the system and the information being generated received also a high rating. The efficiency, functionality, and simplicity were deployed to the system that confirms its applicability to the organization. This further confirms that the data gathering conducted by the researcher was effective and comprehensive since this data will be processed into information.

\begin{tabular}{|c|c|c|}
\hline Criteria & Total & Mean \\
\hline Accuracy & $\mathbf{1 2 6}$ & 4.20 \\
\hline Audibility & $\mathbf{1 2 5}$ & 4.17 \\
\hline Communication & $\mathbf{1 3 2}$ & 4.40 \\
\hline Completeness & $\mathbf{1 3 1}$ & 4.37 \\
\hline Conciseness & $\mathbf{1 3 1}$ & 4.37 \\
\hline $\begin{array}{c}\text { Consistency and } \\
\text { understandability }\end{array}$ & $\mathbf{1 3 3}$ & 4.42 \\
\hline Controllability & $\mathbf{1 3 0}$ & 4.35 \\
\hline Data commonality & $\mathbf{1 2 4}$ & 4.13 \\
\hline Decomposability & $\mathbf{1 2 4}$ & 4.13 \\
\hline Error tolerance & $\mathbf{1 2 1}$ & 4.03 \\
\hline Execution efficiency & $\mathbf{1 2 7}$ & 4.23 \\
\hline Expandability & $\mathbf{1 2 9}$ & 4.30 \\
\hline Generality & $\mathbf{1 2 7}$ & 4.23 \\
\hline Hardware independence & $\mathbf{1 2 5}$ & 4.17 \\
\hline Instrumentation & $\mathbf{1 2 6}$ & 4.20 \\
\hline Modularity & $\mathbf{1 2 4}$ & 4.13 \\
\hline Observability & $\mathbf{1 3 0}$ & 4.32 \\
\hline Operability & $\mathbf{1 3 0}$ & 4.34 \\
\hline Security & $\mathbf{1 3 2}$ & 4.40 \\
\hline Self-documentation & $\mathbf{1 2 7}$ & 4.23 \\
\hline Simplicity & $\mathbf{1 2 8}$ & 4.27 \\
\hline Software system & $\mathbf{1 2 8}$ & 4.27 \\
\hline independence & $\mathbf{1 3 0}$ & 4.33 \\
\hline Traceability & $\mathbf{1 3 2}$ & 4.40 \\
\hline Training & & \\
\hline Softwan & $\mathbf{V a}$ & \\
\hline
\end{tabular}

Table 9. Software Development Validation/Evaluation Responses 


\section{Size-oriented metrics}

Table 4 shows the Size-Oriented Metrics of DILG Negros Occidental CTIMS with a total LOC of 299,396, an effort of 90 days, and priced at Php 132,000, with a Page Documentation of around 160,165 errors and 74 defects during the development phase and one developer. The derived value of the Size-Oriented Metrics was utilized to compute the project measurement.

\section{Complexity Adjustment Responses}

Based on Table 8, the total count/complexity multiplier is 50 . The formula was derived based on the total function point, which is 487.6 , will be multiplied with the rate per function point, which is Php800, and will result in the final cost of the system. The final system cost is Php 390,080 .

\section{Conclusion.}

The utilization of the DILG Negros Occidental CTIMS paved the way for the ease of the operation in managing all the CTs provincewide. The automated system improved the processes of the CT Task team compared to the manual operations and is expected to increase the productivity, effectivity, and efficiency of DILG Negros Occidental. The establishment of a comprehensive database of the CTs eliminated the probability of data redundancy and loss, and promoted data integrity. The system made the collection of information easy and error-free. The streamlined reporting process eliminated the time-consuming process of collecting uniform ARs from the Field Offices. The document tracker feature replaced the manual entry in the logbook. It also improved the received and released documents reporting. Lastly, FOs can evaluate their respective CTs based on their individual performance and behavior.

\section{References}

[1] Agency Information Collection Activities: COVID-19 Contact Tracing, COVID19 Contact Tracing Scripts, COVID-19 Contact Tracing Form. (2021). Lanham: Federal Information \& News Dispatch, Inc. Retrieved from Research Library https://www.proquest.com/reports/agency-information-collection-activitiescovid-19/docview/2478065259/se-2?accountid=34542

[2] Al-Ani, M. K. (2015). A Strategic Framework to Use Payback Period in Evaluating the Capital Budgeting in Energy and Oil and Gas Sectors in Oman. International Journal of Economics and Financial Issues, 5(2), 469-475.

[3] Amade, Benedict \& Akpan, Edem. (2014). Project Cost Estimation: Issues and the Possible Solutions. International Journal of Engineering and Technical Research. 2. 181-188. Retrieved from https://www.researchgate.net/publication/280805190_Project_Cost_Estimation_I ssues_and_the_Possible_Solutions

[4] Amraoui, Soumaya \& Elmaallam, Mina \& Bensaid, Hicham \& Kriouile, Abdelaziz (2019). Information Systems Risk Management: Literature Review. Computer and Information Science. 12. 1. 10.5539/cis.v12n3p1. 
[5] Analysis of Software Quality Using Software Metrics. International Journal on Computational Science \& Applications. 8. 11-20. 10.5121/ijcsa.2018.8502).

[6] Beckwith, F. (2020). "Business Analytics Revisited: A Gap Analysis of Research and Practice" ACIS 2020 Proceedings. 60. https://aisel.aisnet.org/acis2020/60

[7] Connolly, T. \& Begg, C. (2015). Database Systems: A Practical Approach to Design, Implementation, and Management, 6th Edition. Cenveo Publishing Services

[8] Coronavirus Disease (COVID-19): Contact Tracing. Who.int. (2021). Retrieved 10 February 2021, from https://www.who.int/news-room/q-a-detail/coronavirusdisease-covid-19-contact-tracing.

[9] COVID-19 and Your Health. Centers for Disease Control and Prevention. (2021). Retrieved 10 February 2021, from https://www.cdc.gov/coronavirus/2019-ncov/daily-life-coping/contacttracing.html

[10] Demirel, Senay \& Das, Resul. (2018). Software requirement analysis: Research challenges and technical approaches. 1-6. 10.1109/ISDFS.2018.8355322.

[11] Derda, M (2020, September 5). What is a data dictionary? Retrieved from https://www.trifacta.com/blog/data-dictionary.

[12] Di Pietro, G., Biagi, F., Dinis Mota Da Costa, P., Karpinski, Z. and Mazza, J., The likely impact of COVID-19 on education: Reflections based on the existing literature and recent international datasets, EUR 30275 EN, Publications Office of the European Union, Luxembourg, 2020, ISBN 978-92-76-19937-3, doi:10.2760/126686, JRC121071.

[13] Haleem, A., Javaid, M., \& Vaishya, R. (2020). Effects of COVID-19 pandemic in daily life. Current medicine research and practice, 10(2), 78-79.

https://doi.org/10.1016/j.cmrp.2020.03.011

[14] Honglei, T., Wei, S., \& Yanan, Z. (2009). "The Research on Software Metrics and Software Complexity Metrics," 2009 International Forum on Computer Science-Technology and Applications, 2009, pp. 131-136, doi: 10.1109/IFCSTA.2009.39.

[15] Ibrahim, Rosziati \& Yen, Siow. (2010). Formalization of the Data Flow Diagram Rules for Consistency Check. International Journal of Software Engineering \& Applications. 1. 10.5121/ijsea.2010.1406.

[16] Pan American Health Organization (2020, May 12). COVID-19 and the Importance of Strengthening Information Systems. Retrieved from https://Iris.Paho.Org/Bitstream/Handle/10665.2/52127/COVID19FactsheetIS4H_eng.Pdf?Sequence=14\&isAllowed=y.

[17] Paradis, E., O'Brien, B., Nimmon, L., Bandiera, G., \& Martimianakis, M. A. (2016). Design: Selection of Data Collection Methods. Journal of graduate medical education, 8(2), 263-264. https://doi.org/10.4300/JGME-D-16-00098.1

[18] Pountney, Philip. (2013). IMPORTANCE OF RESOURCE PLANNING The importance of resource planning during the initiation stage of an IT Project. Retrieved from https://www.researchgate.net/publication/340883012_IMPORTANCE_OF_RES OURCE_PLANNING_The_importance_of_resource_planning_during_the_initi ation_stage_of_an_IT_Project 
[19] Proclamation No. 922 (2020). Declaring a State of Public Health Emergency throughout the Philippines. Retrieved from http://ulap.net.ph/ulapnews/advisories/441-proclamation-no-922.html

[20] Risk Mitigation Planning, Implementation, And Progress Monitoring (n.d.) Retrieved from https://www.mitre.org/publications/systems-engineeringguide/acquisition-systems-engineering/risk-management/risk-mitigationplanning-implementation-and-progress-monitoring

[21] Schofield, Joseph R. The Use of Function Points for Software Estimation and Measurement. United States. Retrieved from https://www.osti.gov/servlets/purl/1147515

[22] Scott, B. (2020, October 20). Importance of Project Schedule and Cost Control in Project Management. Retrieved from https://www.globalknowledge.com/usen/resources/resource-library/articles/importance-of-project-schedule-and-costcontrol-in-project-management/\#gref

[23] SDLC - Agile Model. (2001) SDLC - Agile Model. Retrieved from https://www.tutorialspoint.com/sdlc/sdlc_agile_model.htm

[24] Sharma, Sheetal \& Sarkar, Darothi \& Gupta, Divya. (2012). Agile Processes and Methodologies: A Conceptual Study. International Journal on Computer Science and Engineering. 4. Retrieved from https://www.researchgate.net/publication/267706023_Agile_Processes_and_Met hodologies_

[25] A_Conceptual_Study/citation/download

[26] Shi, Wei \& Corriveau, Jean-Pierre. (2013). On Acceptance Testing. 7.Retrieved from https://www.researchgate.net/publication/261135731_On_Acceptance_Testing

[27] Short Note on Size-Oriented Metrics (2020). Retrieved from https://www.geeksforgeeks.org/short-note-on-size-oriented-metrics/

[28] Soumaya A., \& Mina E \& Hicham B., \& Abdelaziz K (2019) Retrieved from https://www.ccsenet.org/journal/index.php/cis/article/view/0/39795\%20

[29] Talal, R. (2017) Software Engineering - Software Metrics Retrieved from https://uomustansiriyah.edu.iq/media/lectures/5/5_2017_11_25!11_06_01_AM.p df

[30] Tang, Antony \& Aleti, Aldeida \& Burge, Janet \& Vliet, Hans. (2010). What makes

[31] software design effective? Design Studies - DESIGN STUD. 31. 614-640. 10.1016/j.destud.2010.09.004.

[32] Thiemo Fetzer and Thomas Graeber. (2021). Measuring the scientific effectiveness of contact tracing: Evidence from a natural experiment Retrieved from https://www.pnas.org/content/118/33/e2100814118

[33] Uddin, Azeem \& Anand, Abhineet. (2019). Importance of Software Testing in the

[34] Process of Software Development. 2321-0613. Retrieved from https://www.researchgate.net/publication/331223692_Importance_of_Software_ Testing_in_the_Process_of_Software_Development

[35] Waykar, Yashwant. (2015). role of use case diagram in software development. International Journal of Management and Economics. Retrieved from 
https://www.researchgate.net/publication/322991847_role_of_use_case_diagram _in_software_development

[36] With the approval of Bayanihan 2, DILG begins hiring 50,000 contact tracers (2020). Retrieved from https://dilg.gov.ph/news/With-the-approval-ofBayanihan-2-DILG-begins-hiring-50000-contact-tracers/NC-2020-1310

[37] Zamfir M \& Manea M Daniela \& Ionescu L, (2016). "Return on Investment Indicator for Measuring the Profitability of Invested Capital," Valahian Journal of Economic Studies, Sciendo, vol. 7(2), pages 79-86, December. Retrieved from

[38] https://ideas.repec.org/a/vrs/vaecst/v7y2016i2p79-86n10.html

[39] Zhang, M., Chow, A., \& Smith, H. COVID-19 Contact-Tracing Apps: Analysis of the Readability of Privacy Policies. J Med Internet Res 2020;22(12):e21572. URL: https://www.jmir.org/2020/12/e21572. DOI: 10.2196/21572 